\title{
ROLE OF HUMAN RESOURCE, FACILITIES, AND INFRASTRUCTURE IN EARLY WARNING SYSTEM OF DENGUE HAEMORRHAGIC FEVER IN DUMAI, RIAU
}

\author{
Dwie Novitaroza, Zulfendri, Nurmaini \\ Masters Program in Public Health, Universitas Sumatera Utara
}

\begin{abstract}
Background: Dengue/dengue hemorrhagic fever (DF/DHF) has been one of the most important resurgent tropical diseases in the past 3 decades, with expanding geographical distribution of both the viruses and the mosquito vectors, increased frequency of epidemics, development of hyper-endemicity (co-circulation of multiple virus serotypes), and the emergence of DHF in new areas. Early warning systems (EWS) are in most instances, timely surveillance systems that collect information on epidemic-prone diseases in order to trigger prompt public health interventions. An EWS is an instrument for communicating information about impending risks to vulnerable people before a hazard event occurs, thereby enabling actions to be taken to mitigate potential harm, and sometimes, providing an opportunity to prevent the hazardous event from occurring. This study aimed to describe the role of human resource, facilities, and infrastructure in EWS of dengue haemorrhagic fever in Dumai, Riau.
\end{abstract}

Subjects and Method: This was a qualitative study conducted in Dumai, Riau. A sample of informants was selected for this study, including personnel from Dumai City Health Office, health center doctors, and communicable disease control personnel. The study theme was adequacy of resources for DHF EWS. The data were collected by in-depth interview, observation, and document review.

Results: The qualification, competence, and number of human resources for DHF surveillance and EWS at Dumai Municipality Health Office had not conformed with the standards. Facilities and infrastructure, including computing devices, were sufficient in number. However, Standard Operating Procedures (SOP) for DHF surveillance program and EWS was non-existent.

Conclusion: Health personnel for DHF control and prevention are limited in number competence and qualification. SOP for DHF surveillance program and EWS is non-existent.

Keywords: Dengue Haemorrhagic Fever, human resource, facilities, infrastructure, warning system

\section{Correspondence:}

Dwie Novitaroza. Masters Program in Public Health, Universitas Sumatera Utara, Medan, North Sumatera. Email: uwieoza86@gmail.com. Mobile: o81365218120 